Article

\title{
Factors Influencing Household Food Security in West Africa: The Case of Southern Niger
}

\author{
Seydou Zakari ${ }^{1, \dagger}$, Liu Ying ${ }^{1, *}$ and Baohui Song ${ }^{2, \dagger}$
}

1 College of Economics and Management, Huazhong Agricultural University, Wuhan 430070, China;

E-Mail: zakaryaou@yahoo.com

2 College of Agriculture, California State University, Chico, CA 95973, USA;

E-Mail: bsong@csuchico.edu

$\dagger$ These authors contributed equally to this work.

* Author to whom correspondence should be addressed; E-Mail: liuyhzau@gmail.com;

Tel: +86-1366-7201-370,+86-275-982-4673; Fax: +86-278-739-6057.

Received: 10 January 2014, in revised form: 31 January 2014 / Accepted: 11 February 2014 /

Published: 5 March 2014

\begin{abstract}
Food insecurity is a major challenge for Niger and for many African countries. The purpose of this study is to investigate the factors affecting household food security in Niger. Based on survey data covering 500 households, drought, high food prices, poverty, soil infertility, disease and insect attacks are reported by the respondents to be the main causes of food insecurity. The empirical results from logistic regression revealed that the gender of the head of household, diseases and pests, labor supply, flooding, poverty, access to market, the distance away from the main road and food aid are significant factors influencing the odds ratio of a household having enough daily rations. Another important finding is that female headed households are more vulnerable to food insecurity compared to male headed households. The findings of this study provide evidence that food insecurity continues to affect the Nigerien population.
\end{abstract}

Keywords: food security; household; coping strategies; causes of vulnerability; Niger 


\section{Introduction}

Maintaining food security at the country level and household level is still a major challenge for many developing countries. According to the Food and Agriculture Organization [1], about 870 million people are estimated to have been undernourished (in terms of dietary energy supply) in the period 2010-2012. This figure represents $12.5 \%$ of the global population. The vast majority of these, 852 million live in developing countries, where the prevalence of undernourishment is now estimated at $14.9 \%$ of the population.

FAO [2] defined food security as a situation "when people, at all times, have physical and economic access, safe and nutritious food to meet their dietary needs and food preferences for an active and healthy life". According to this definition, there are three important interlinked components of food security: availability, access and utilization. Therefore, a household is food secure in a given time period if it has enough food to provide its members all the usual meals in a day, for the entire period. Otherwise, the household is food insecure. The ability to ensure adequate food security hinges on the ability to identify vulnerable households. The degree of vulnerability of an individual, household or group of persons is determined by their exposure to the risk factors and their ability to cope with or withstand stressful situations.

In Niger, food security analysis has attracted the attention of the Niger government and many international organizations, due to severe a food crisis experienced in the past in the country. The Nigerien government with the assistance of international institutions, such as FAO and the European Union, used to carry out a joint post-harvest household food security assessment to identify the vulnerable zones and target people for early prevention and management of the food crisis. The World Food Program [3] reported that food insecurity is caused by the uncertainty of climate, the poor performance of the agriculture sector and poverty. Food insecurity significantly affects a large Nigerien population and varies across regions and seasons. According to the United States Agency for International Development [4], on an annual basis, $22 \%$ of Niger's population suffer from chronic food insecurity (per capita consumption of $<1800 \mathrm{kcal} /$ person/day). Food insecure households suffer from a weak livelihood base and risky coping strategies. These households spend up to $72 \%$ of their income on food [5]. Food insecurity is aggravated by high incidences of rural poverty, which translate at the household level into low purchasing power, lack of access to food by vulnerable groups, rampant malnutrition and poor access to health facilities [6]. Niger is one of the world poorest countries, with limited per capita purchasing power; the country has a $63 \%$ poor population. One key determinant of poverty in Niger is overdependence on subsistence farming with limited access to gainful off-farm employment and income-generating activities. This high poverty incidence combined with high population is a major factor affecting household food security.

Despite the tremendous combined efforts of the Nigerien government and many International Organizations and Non-Governmental Organizations (NGOs) in fighting and monitoring hunger, food insecurity still affected a large number of the Nigerien population. Thus, an important question may be raised about the effectiveness and efficiency of the evaluation of food security in the country. According to FAO [7], there is no single measure to analyze the level of the food security of a population, a community or an individual. Food security is highly complex in that it is determined by a range of 
interrelated agro-environmental, socioeconomic and biological factors, all of which have to be addressed to conclude whether food security exists or not.

The main objective of this study is to identify the factors influencing household access to food. This study may also provide much needed baseline information on the food security and may contribute to the existing literature in helping to implement a proper policy against the population's vulnerability to food insecurity. As household food security is subject to change, it is important to investigate its determinants to predict future shocks and also to understand how the household responds to food insecurity.

\section{Materials and Methods}

\subsection{Description of the Study Area}

The survey was conducted in the district of Kollo, Southern Niger, during the period June-July, 2012. The Kollo district lies between longitude $1^{\circ} 30^{\prime}$ and $2^{\circ} 55^{\prime}$ and latitude $12^{\circ} 30^{\prime}$ and $13^{\circ} 53^{\prime}$. It has a total population of over 397,304 inhabitants and a total land mass of $9804 \mathrm{~km}^{2}$. The infrastructures of the district are poorly developed. Agriculture is the main economic activity, exerted by more than $90 \%$ of the population in the region. Agricultural production in the study area is characterized by subsistence farming, where rural household needs determine the scale of production. Millet and sorghum are the main crops cultivated in this area. Crop production depends mainly on a 3-month raining season (July to September), followed by a long dry season. The average annual rainfall ranges between 350 to $450 \mathrm{~mm}$. Small pieces of land, generally inherited, are cultivated by individual owners or sub-owners using the traditional methods of farming systems. The most commonly used agricultural tools include hand tools, which are owned by almost all households. Food crops are grown for home consumption, and only the surplus is sold in local market. Cash crops are grown to earn some extra-money to purchase food that cannot be produced on the farm. Cash crops are often difficult to define, though cowpeas, groundnuts, okra and sesame are considered as cash crops. For those households that owned livestock, bulls are kept for draft power, while milk, meat and hide are sold or used directly by the households. Irrigated rice cultivation is carried out along the Niger River, where farmers are grouped in cooperatives. Off-farm activities are dominated by the cultivation of vegetables and fruits along the Niger River valley and in the lowland areas. Women are mainly involved in the production of vegetables, such as tomatoes and onions. While most villagers are involved in sedentary agriculture, many still combine other activities, such as small trade, animal rearing, etc.

\subsection{Data Collection}

A random sampling approach was adopted, where the questionnaire was administered through individual structured interviews with the heads of the households in 15 selected villages. A total number of 500 households were covered. The survey gathered qualitative and quantitative data pertaining to the social, demographic and economic aspects of the households. We also included items related to the causes of food insecurity in the region, as well as access to the market, receipt of food aid and the distance of the village away from the main road. The information about the background of the head of the household revealed the respondent's age, household size, level of education, main occupation, assets owned and gender. The situation of the stock status was measured through the availability of sufficient 
daily rations for household members, the number of meals taken per day and the number of days per week meat or fish is eaten in the household. The odds of reporting that one often experienced food shock were also included in the analysis. The major food concern of a household is to have enough food to eat, at all times; basically (in terms of quantity and availability), to feed all its members. The nutritional aspect (diet quality) is secondary for most developing countries. The items used in the measurement of relative causes of food insecurity in the area are dummy variables, such as drought, disease and insect attacks, floods, soil infertility, lack of farm inputs, lack of enough land to cultivate, lack of money to buy foodstuffs and high food prices. Because of complex varieties of African households, in this study, we defined a household as people who eat and work together in the family to ensure the production of food and welfare for its members.

\subsection{Statistical Analysis}

In this study, we consider a household as food secure in a given time if it always has enough food to provide to its members in a day for the entire period. Otherwise, the household is considered as food insecure. Since the dependent variable (having enough daily ration) is dichotomous, we used a binary logistic regression model to examine the factors that influence the odds ratio of the household food status. The odds ratio is the ratio of the probability that a household would always have enough daily rations for its members to be food secure (Pi) to the probability of a household not always having enough food to be food insecure $(1-\mathrm{Pi})$. The dependent variable used in the study is a dummy variable that takes the value of one, if the daily ration is always sufficient for household members (food secure); 0 otherwise (food insecure). We estimated sufficient daily rations as a function of several independent variables, as presented in Table 1.

The logistic model of the relationship between the household food security status variable (FSS) and its explanatory variables is specified as follows [8]:

$$
\ln [\mathrm{Pi} /(1-\mathrm{Pi})]=\beta_{0}+\beta_{1} X_{1 i}+\beta_{2} X_{2 i}+\ldots \ldots .+\beta_{17} X_{17 i}
$$

where subscript $i$ denotes the $i$-th observation in the sample, $P$ is the probability of the outcome, $\beta_{0}$ is the intercept term and $\beta_{1}, \beta_{2}, \ldots ., \beta_{17}$ are the coefficients associated with each explanatory variable, $X_{1}, X_{2}, \ldots, X_{17}$.

The estimated coefficients do not directly indicate the effect of change in the corresponding explanatory variables on the probability $(P)$ of the outcome occurring. Rather, the coefficients reflect the effect of individual explanatory variables on the odds ratio of the dependent variable (i.e., the household being food secure or food insecure).

Table 1. Description of variables used in the logistic regression model.

\begin{tabular}{ll}
\hline \multicolumn{1}{c}{ Variables } & \multicolumn{1}{c}{ Definition } \\
\hline Dependent variable & \\
FSS, food security status $(Y)$ & 1 if ration is always enough for household members, 0 otherwise \\
Independent variables & Number of years of age \\
HHAge $\left(X_{1}\right)$ & 1 if household head is male, 0 otherwise \\
HHSex, Gender $\left(X_{2}\right)$ & 1 if household head is literate, 0 otherwise \\
HHE, level of education $\left(X_{3}\right)$ & Number of household members \\
FS, family size $\left(X_{4}\right)$ &
\end{tabular}


Table 1. Cont.

\begin{tabular}{ll}
\hline \multicolumn{1}{c}{ Variables } & \multicolumn{1}{c}{ Definition } \\
\hline Asset $\left(X_{5}\right)$ & 1 if household owns assets, 0 otherwise \\
Drought $\left(X_{6}\right)$ & 1 if food insecurity is caused by drought, 0 otherwise \\
Diseases and insects $\left(X_{7}\right)$ & 1 if food shortage is caused by disease and insect attacks, 0 otherwise \\
Labor $\left(X_{8}\right)$ & 1 if food shortage is caused by lack of enough labor, 0 otherwise \\
Flooding $\left(X_{9}\right)$ & 1 if food shortage is caused by flooding, 0 otherwise \\
Soil infertility $\left(X_{10}\right)$ & 1 if food shortage is caused by soil infertility, 0 otherwise \\
Farm inputs $\left(X_{11}\right)$ & 1 if food shortage is caused by lack of farm inputs, 0 otherwise \\
Land $\left(X_{12}\right)$ & 1 if food shortage is caused by lack enough land to cultivate, 0 otherwise \\
Money $\left(X_{13}\right)$ & 1 if food shortage is caused by lack of money to buy provisions, 0 otherwise \\
Food prices $\left(X_{14}\right)$ & 1 if food shortage is caused by high food prices, 0 otherwise \\
FA, food aid $\left(X_{15}\right)$ & 1 if household used to receive food aid, 0 otherwise \\
Market $\left(X_{16}\right)$ & 1 if household has access to market, 0 otherwise \\
Distance from main road $\left(X_{17}\right)$ & Number of km of the village from the main road \\
\hline
\end{tabular}

\section{Descriptive Results}

\subsection{Household Characteristics}

Table 2 presents the demographic and socioeconomic characteristics of the respondents. Up to $90 \%$ of the household heads exert farming as a main occupation. Few of the respondents practice fishing $(3.2 \%)$, trade $(1.8 \%)$, public workers $(3.2 \%)$ and animal rearing $(0.6 \%)$. The average age is 45.82 years-old, which implies that household heads have the ability to use their own labor to farm. FAO classified the average of economically productive population within the range of 15-64 years-old. In the assessment of the assets of the household, we only considered two main items (ownership of land and animal). There are $97.8 \%$ of people sampled who were found to own land. In Niger, $76 \%$ of land is traditionally inherited. Unfortunately, with the high population growth, available land is continuously being divided among families and being overused. The scarcity of land sometimes causes many conflicts among families and also between farmers and pastoralists. Rural farming families have landholdings averaging five acres of dry land. Some families also have access to small plots (less than one hectare) of irrigated land. The deteriorating quality of the soil has caused farmers to expand the area of land cultivated, often encroaching on land used by pastoralists for grazing and creating the potential for conflict [9]. Table 2 also shows that the average family size is relatively big (eight persons), which is important for generating a labor supply, the vital factor for agricultural production, especially in those poor developing countries. There are $70 \%$ of respondents to have reported to own animals. Niger farmers usually rear animals, which serve as critical input in farm operations and an important source of capital for the household. Livestock can be considered as insurance for the household, as animals are sold to purchase food during shock periods. Concerning gender and the education of the respondents, the results show a high number of males (87.4\%) and a low level of literacy (26.6\%). 
Table 2. Summary of the demographic and socio-economic characteristics of respondents.

\begin{tabular}{lll}
\hline \multirow{2}{*}{ Characteristics } & \multicolumn{2}{c}{ Statistics } \\
\cline { 2 - 3 } & Respondents & Unit \\
\hline Number of respondents & 500 & Number \\
Age of head of household & 45.82 & Mean \\
Household size & 8.19 & Mean \\
Gender & & \\
Male & 87.4 & $\%$ \\
Female & 12.6 & $\%$ \\
Level of Education & & \\
No formal education & 73 & $\%$ \\
Primary & 18 & $\%$ \\
Secondary & 8.6 & $\%$ \\
Others & 4 & $\%$ \\
Main Occupation of Head of Household & & \\
Farmers & 89.4 & $\%$ \\
Fishermen & 3.2 & $\%$ \\
Traders & 1.8 & $\%$ \\
Herders & 0.6 & $\%$ \\
Public workers & 1.8 & $\%$ \\
Others & 3.2 & $\%$ \\
Assets & & \\
Land + animals & 56.8 & $\%$ \\
Land + animal + others & 13 & $\%$ \\
Land only & 26 & $\%$ \\
Animal only & 1 & $\%$ \\
Others & 3.2 & $\%$ \\
\hline
\end{tabular}

\subsection{Source of Household Food}

As presented in Table 3, the primary source of food consumed in the households is from their own production. More than $80 \%$ of the Niger population depends on crop production and animal rearing for their livelihood. Domestic food production plays an important role in Niger food security. The market is the second source of households' food supply. Though the majority of households is engaged in farming, almost all households are net purchasers of food. Most of the households do not produce sufficient quantities to cover the consumption needs over the season. Some of them sell part of their production to cover the production expenses and other needs, such as weddings and children school fees.

Table 3. Sources of household food.

\begin{tabular}{lcc}
\hline \multicolumn{1}{c}{ Sources of household food } & Frequency $(\boldsymbol{N})$ & Percent \\
\hline Own production only & 5 & $1 \%$ \\
Own production and market purchase & 425 & $85 \%$ \\
Market purchase only & 26 & $5.2 \%$ \\
Others & 44 & $8.8 \%$ \\
Total & 500 & $100 \%$ \\
\hline
\end{tabular}

The prevalence of food insecurity is reported in Table 4 . Out of 500 respondents, $92.6 \%$ fear running out of food in the coming days. The average daily meal number is 2.57 , which is less than the normal three meals per day. The average meat or fish intake is two to three days per week. This attests to the 
poor quality of the diet of the households. Some households eat meat or fish only during the weekly market day, once or twice a week. Thus, even though they intend to purchase meat, they do not always have access to markets where meat is available for sale. According to surveys conducted by the Niger Government on household budgets, over $80 \%$ of daily caloric consumption came from cereals (millet, sorghum and other cereals) in 2005 and $70 \%$ in 2006. In 2005, there were $59 \%$ of the population consuming less than the minimum caloric requirement of 2,100 calories per day for an adult population, as defined by the World Health Organization, while in 2006, about 52\% of the population consumed less that this minimum requirement [3]. Only $48 \%$ of respondents reported that their daily rations had been always enough for their members. These statistics indicate a high prevalence of food insecurity in the region. We have to note that the period between June-July is a hard period of the year, as most households that depend on their own production for food may have already finished their stocks and relied solely on the market for food. According to Humanitarian Exchange Magazine [10], in April, 2005, a typical household in Niger depended on market purchases for $90 \%$ of its food.

Table 4. Household food availability status.

\begin{tabular}{lcc}
\hline \multicolumn{1}{c}{ Items } & Frequency $(\boldsymbol{N})$ & \% or Mean \\
\hline Fear that food will run out & 463 & 92.6 \\
Number of meals per day (mean) & 500 & 2.57 \\
Number of days meat or fish is taken per week (mean) & 500 & 2.38 \\
Ration always sufficient for household members & 240 & 48 \\
\hline
\end{tabular}

\subsection{Causes of Food Insecurity}

Through the survey, we identified several possible causes of food insecurity in Niger, as shown in Table 5. Among them, drought seems to be the major cause of food insecurity in Niger. Out of 500 respondents, 94.2\% agreed that drought contributes to household food insecurity. Nigerien agriculture is highly affected by the timeliness and irregularity in rainfalls and other climatic factors. Low precipitation is the main limiting factor for crop production. Rainfall is very low and erratic, with periods of drought often followed by devastating flash floods. Water resources are limited, unevenly distributed and not easily accessible. As a result, a large part of the country is unsuitable for rain-fed agriculture, and natural pastures are being depleted. Drought often results in increases in the prices of food products, and most households who depend solely on their own production lack purchasing power to buy food to satisfy the needs of their members. $71.8 \%$ of the households sampled agreed that having enough daily ration is affected by high food prices. Soil infertility is another major constraint to Nigerien agriculture. $62 \%$ of respondents reported that food insecurity is related to soil infertility. Land degradation, particularly due to soil fertility depletion and soil erosion, is a serious constraint to agricultural productivity. Due to harsh environmental conditions, not all crops can be grown in Niger, thus limiting agricultural production to a few crops. Soils in Niger are inherently fragile, low in carbon and poor in plant nutrients. Therefore, when these soils are poorly managed (as is often the case), the outcome in terms of human welfare and environmental sustainability can be dramatic. Limited farm inputs seriously affect agricultural productivity. When farmers cannot afford yield-enhancing inputs, low productivity and food insecurity can follow. Most traditional farms have inadequate capital for the purchase of costly inputs, such as farm machinery, fertilizer, herbicide and pesticide, which contribute to 
the low cereal production. Farm operations, from land clearing to crop harvesting and processing, are carried out by hand using simple tools, such as a hoe, cutlass, axe, sickle and other local farm implements, by the majority of Niger farmers. In general, technology-based agriculture has not come to Niger on a significant scale. In short, the absence of new technologies in agriculture will slow the growth of agricultural productivity and the reduction of rural poverty. Agricultural techniques are still rudimentary; there are a few tractors in use (only 130 in 1998). Pest and disease attacks of crops are also serious problems affecting the grain production in Niger. Some of the common pests of cereal crops in Niger are locust, termites, birds and mammals, like rats, while diseases include smut, blight and root rot, etc. Niger's food crisis in 2005 has been attributed to a locust invasion and drought that devastated crop production. Flooding also often affects Niger crop farms. Rice farms along the Niger River are usually flooded, thus reducing harvest and production areas. The high poverty index among the Nigerien population affects the daily ration of many households. Niger is classified as one of the world's poorest countries. Even though food is available at market, many households do not have money to purchase food. Labor constraint is not a major cause for household food insecurity, despite $41.6 \%$ of respondents agreeing that it affects the daily ration, as the average number of a family size is high. Indeed, there are some families where members used to migrate to neighboring countries, which can affect labor availability.

Table 5. Causes of food insecurity.

\begin{tabular}{lcc}
\hline \multirow{2}{*}{ Causes of food insecurity } & \multicolumn{2}{c}{ Responses } \\
\cline { 2 - 3 } & Frequency $(\boldsymbol{N})$ & Percent \\
\hline Drought & 471 & $94.2 \%$ \\
Diseases and insects & 289 & $57.8 \%$ \\
Lack of enough labor & 208 & $41.6 \%$ \\
Flooding & 181 & $36.2 \%$ \\
Soil infertility & 310 & $62.0 \%$ \\
Lack of enough inputs & 292 & $58.4 \%$ \\
Land not enough & 226 & $45.2 \%$ \\
Lack of money & 282 & $56.4 \%$ \\
Increased in food prices & 359 & $71.8 \%$ \\
\hline
\end{tabular}

\section{Empirical Results and Discussion}

\section{Factors Affecting Food Security}

The binary logistic regression results in Table 6 show the determinants of food security (ration always enough for all household members). The logistic regression model indicated that the overall predictive power of the model (75\%) was quite high, while the significant Chi square $\left(\chi^{2}=184.057\right.$, $p<0.01$ with $\mathrm{df}=17)$ and pseudo- $\mathrm{R}^{2}$ were indicative of the strength of the joint effect of the covariates on the probability of a sufficient daily ration of the household members. The Wald values demonstrated the relative contribution of individual variables to the odds probability of the household to have enough food for its members. The regression model estimates which factors are associated with significantly increased odds of having enough daily rations for household members. 
Table 6. Logistic regression coefficients of the factors affecting the household food security status.

\begin{tabular}{|c|c|c|c|c|c|}
\hline Variables & $\boldsymbol{B}$ & $\begin{array}{c}\text { Standard } \\
\text { Error }\end{array}$ & Wald & p-value & $E(B)$ \\
\hline EHH & 0.227 & 0.270 & 0.705 & 0.401 & 1.255 \\
\hline Gender & 0.955 & 0.365 & 6.993 & $0.008 * * *$ & 2.624 \\
\hline HHAge & 0.003 & 0.010 & 0.103 & 0.749 & 1.003 \\
\hline HSize & -0.043 & 0.028 & 2.491 & 0.114 & 0.957 \\
\hline Asset & 0.880 & 1.023 & 0.740 & 0.390 & 2.412 \\
\hline Drought & 0.160 & 0.543 & 0.087 & 0.768 & 1.173 \\
\hline Diseases and insects & -0.586 & 0.313 & 3.515 & $0.061 *$ & 0.556 \\
\hline Labor & 0.618 & 0.303 & 4.159 & $0.041 * *$ & 1.854 \\
\hline Floods & -0.784 & 0.311 & 6.347 & $0.012 * *$ & 0.457 \\
\hline Soil infertility & 0.131 & 0.280 & 0.217 & 0.641 & 1.140 \\
\hline Farm inputs & -0.047 & 0.292 & 0.026 & 0.872 & 0.954 \\
\hline Land & 0.214 & 0.284 & 0.570 & 0.450 & 1.239 \\
\hline Lack of money & -1.181 & 0.309 & 14.598 & $0.000 * * *$ & 0.307 \\
\hline Food prices & -0.440 & 0.288 & 2.339 & 0.126 & 0.366 \\
\hline Market & -1.081 & 0.294 & 13.538 & $0.000 * * *$ & 0.339 \\
\hline Distance from main road & 0.148 & 0.022 & 44.671 & $0.000 * * *$ & 1.160 \\
\hline FA & -0.974 & 0.261 & 13.909 & $0.000 * * *$ & 0.378 \\
\hline Constant & -0.135 & 1.233 & 0.012 & 0.913 & 0.874 \\
\hline Pseudo-R ${ }^{2}$ & 0.411 & & & & \\
\hline LR test ${ }^{\mathrm{a}}$ & 508.442 & & & & \\
\hline
\end{tabular}

Notes: a likelihood ratio (LR) test is used to test the null hypothesis that there is no relationship between the log of odds of household food security and the set of independent variables included in the model. *,** and *** indicate significance at $10 \%, 5 \%$ and $1 \%$ respectively.

We found a significant positive relationship between the gender of the head of the household and the food security. Male-headed households are more food secure compared to female headed households. The expected odd ratio of gender is equal to 2.64 which indicate that the male-headed households have 2.6 times chance to be food secure compared to female-headed households. Similar results were found by Felker-Kantor and Wood [11] in a study carried out on female-headed households and food insecurity in Brazil. They revealed that the odds of food insecurity are higher among female-headed households compared to male-headed households. In Niger, female-headed households are relatively poorer, and most of them are widows. The dummy variable (disease and insect attacks) is found to have a significant negative relationship with the dependent variable. Disease and insect attacks affect household food production, thereby contributing to food insecurity. The floods coefficient exerts a negative and significant effect on household food security. Flood is associated with a high production loss or even leaving the farm uncultivated, thus affecting household food availability. The results also revealed a negative and significant association between the lack of money (poverty) and food security. The high poverty index among the population is a major factor causing food insecurity in Niger. Many households, even though food is available at market, lack purchasing power to provide food for their members. According to a World Bank report [6], the prevalence of poverty and extreme poverty are relatively higher in rural areas, with $65.7 \%$ of the population in rural areas living below the poverty line, 
compared to $55.5 \%$ in urban areas. The distance from the main road can influence positively and significantly the odds probability of household food security. Infrastructure, such as roads, is important in the quick transportation of agricultural products, thereby facilitating market integration among regions. This will help to move the products from surplus areas to deficit areas to reduce the impact of food shocks on households.

In addition, and unexpectedly, the results revealed a positive coefficient for labor shortage, while coefficients for access to the market and food aid are found to have a negative and significant influence on the odds of the probability of a household to be food secure. The positive effect on the probability of a household's food security may be because of the fact that labor is not well exploited. Lack of labor will have a dramatic impact on agricultural production and household food security. Because of low mechanization in Nigerien agriculture, human labor is crucial for land preparation, weeding and harvesting processes. Market access is where a household can purchase food at any time of the year, thus it plays a role in the household food availability system. However, the coefficient of market access revealed a negative influence on the odds ratio of the household having enough daily rations. We have to note that there is a negative impact of market forces from the supply and demand sides sometimes affecting household food availability. Farmers usually sell their products at lower prices during harvest periods, because they need cash, then rely on the market for supply after a few months, when the food prices may be at their peaks. The results show that food aid influences negatively and significantly the household food security. Food aid is frequently part of the international response to a national or economy-wide extreme crisis. These crises pose an immediate or imminent threat to lives, livelihoods, short-term stability and longer-term development. Barrett and Maxwell [12] argued that food aid contributes to economic development and protects basic human rights, where the aid fills a severe food gap. Food aid transfers play a safety net role by reducing vulnerability and protecting productive assets. Barrett [13] revealed that food aid decreased government support to agriculture in the long-run and caused distortion in the local price of food items. For instance, the income of a rice farmer will be affected by the subsidized sale of rice from the government to vulnerable people, as it fluctuates market price and reduces the household purchasing power. Indeed, food aid helps to relieve the temporary hunger of affected people, but may have a long-term negative effect on local food production, as many households will intend to rely on aid. Governments that used to receive international food aid tend to rely on it and will sometimes not give appropriate attention to their domestic agricultural production.

\section{Conclusion and Policy Implications}

The findings of this study provide evidence that food insecurity continues to affect the Nigerien population and the development of the country. The results attest to the high prevalence of food insecurity among households; less than $10 \%$ of respondents may be considered food secure (as $92.6 \%$ of respondents reported fearing running out of food stocks). Even though food may be available at all times for household members in enough quantity, there is no guarantee that the diet provides them the required calories needed to be food secure. For example, if a household produces only millet, which forms the main component of the diet and can sustain the household food availability from one season to the next, the household considers itself to be food secure. Yet, from a nutritional point of view, the household could be food insecure, because such a diet would be deficient in proteins, oils and vitamins. 
The vulnerability to food insecurity is more severe during poor harvest seasons in which most households were unable to produce enough food to keep feeding their members throughout the year. The odds of enough food for household members is influenced significantly by a number of factors, such as poverty, drought, floods, diseases and pest attacks; the gender of the head of the household, access to market, food aid, the distance of the village from the main road and labor supply. The negative impact of these factors does not only affect household food security, but also has long-term consequences for life and survival of household members as a unit. To achieve this, as the primary source of food for $80 \%$ of the Nigerien population is from their own production, which is the case of most sub-Saharan countries, improving household-level food production through assistance from the government, adequate supply of farm inputs and ensuring their proper use in the production process will help to increase productivity. Investments in irrigation are crucial to increase food availability in Niger, and reducing labor migration through the development of off-farm employment for rural dwellers is essential. The majority of households rely on the market as their secondary source of food supply. Therefore, facilitating market integration through the development of local infrastructures and proper trade policies to ease the circulation of agricultural products between countries or regions will help to move foods from surplus producing areas to food shortage places to reduce the impact of shocks. National and international development organizations should concentrate their projects on activities that will raise rural and urban incomes to alleviate poverty and to promote household welfare. The study revealed that female-headed households are more vulnerable to food insecurity compared to male-headed households. Therefore, more attention and assistance should be given to them during a food crisis. In Africa, women play a major role in household food security. They are the primary caregivers and contribute to acquiring or producing food for the household. Disease, pest attacks and floods significantly and negatively influence the food security of the household. Proper prevention measures should be taken at the national and household levels to avoid production losses from diseases, pests and floods.

\section{Acknowledgments}

We are grateful for the financial support of the project of New Century Excellent Talents (NCET-12-0868) and the project (2013PY017) of the Fundamental Research Funds for the Central Universities of China.

\section{Author Contributions}

Field survey, data analysis and methodology performed by Seydou Zakari. The Writing and result interpretations achieved by Liu Ying. Tables, parts of the writing and English language editing are from Song Baohui.

\section{Conflicts of Interest}

The authors declare no conflict of interest. 


\section{References and Notes}

1. Food and Agriculture Organization. Undernourishment around the World in 2012; Food and Agriculture Organization: Rome, Italy, 2012.

2. Food and Agriculture Organization. Rome Declaration on World Food Security and World Food Summit Plan of Action. In Proceedings of the World Food Summit, Rome, Italy, 1-17 November 1996; Food and Agriculture Organization: Rome, Italy, 1996.

3. World Food Program. Enquete Sur la Securite' Alimentaire En Situation D'urgence (Efsa) au Niger; WFP: Niamey, Niger, 2005. (In French)

4. United State Agency for International Development. Usaid Office of Food for Peace Niger Bellmon Estimation. Available online: www.usaidbest.org/docs/NigerBellmon2011.pdf (accessed on 10 December 2012).

5. World Health Organization. Food Security in Niger. Available online: www.who.int/hac/ crises/ner/appeal/Niger_advocacy_Oct06.pdf (accessed on 15 March 2013).

6. World Bank. Niger Food Security and Safety Nets; Report No. 44072-NE; World Bank: Washington, DC, USA, 2009. Available online: http://reliefweb.int/sites/reliefweb.int/files/ resources/fullreport_154.pdf(accessed on 19 September 2012).

7. Food and Agriculture Organization. Trade Reforms and Food Security: Conceptualizing the Linkages. Avaliable online: ftp://ftp.fao.org/docrep/fao/005/y4671e/y4671e00.pdf (accessed on 14 April 2013).

8. Neupane, R.P.; Khem, R.S.; Gopal, B.T. Adoption of agroforestry in the hills of Nepal: A logistic regression analysis. Agr. Syst. 2002, 72, 177-196.

9. Food and Agriculture Organization. The Millennium Development Goals: The Road Ahead. Available online: www.fao.org/mdg/ (accessed on 12 February 2013).

10. Ibrahim, L.; Geert, B. Cross-border trade and food markets in Niger: Why market analysis is important for humanitarian action. Humanit. Exch. Mag. 2007, 38, 24-27.

11. Felker-Kantor, E; Wood, C.H. Female-headed households and food insecurity in Brazil. Food Secur. 2012, 4, 607-617.

12. Barrett, B.C.; Maxwell, D.G. Food Aid after Fifty Years-Recasting Its Role; Routledge: London, UK, 2005.

13. Barrett B.C. Food Aid's Intended and Unintended Consequences Background; Paper for Food and Agriculture Organization; Food and Agriculture Organization: Rome, Italy, 2006.

(C) 2014 by the authors; licensee MDPI, Basel, Switzerland. This article is an open access article distributed under the terms and conditions of the Creative Commons Attribution license (http://creativecommons.org/licenses/by/3.0/). 